\title{
Comprehensive benefits analysis and economic evaluation of microgrid
}

\author{
Jin Xiaoling* \\ State Grid Energy Research Institute, Beijing 102209, China
}

\begin{abstract}
This paper is dedicated to analyze the economic issues related to the operation of microgrid system as well as exploring its benefits in improving reliability, energy saving and consumption reduction, environmental protection, investment deferral in transmission and distribution grids from the social perspective. It analyzes its cost and benefits in typical situations by the 2 typical cases of grid-connected and off-grid microgrids compared with that of distributed generator directly connected to power grid. And the key factors affecting the economy of microgrid are discussed.
\end{abstract}

Keywords: Microgrid, comprehensive benefit, cost, economic evaluation

\section{Introduction}

Microgrid has effectively mitigated the effect of distributed generation on power grid, thus boasting excellent development potential. Micro-grid brings us not only direct economic benefits but also indirect benefits such as energy saving, emission reduction, loss reduction, reliability improvement, and deferral of grid construction, etc. The economic evaluation on microgrid should not be limited to its finance only. We should also analyze its net contributions to the national economy and evaluate its rationality to the national economy according to the principle of reasonable resources distribution from the perspective of the whole society. The calculation result shows that we should not only consider its economic benefits when constructing and investing in microgrid in low-carbon situation. Its comprehensive social benefit is equally a key factor that we should take into consideration. The importance of users' load and the construction site of microgrid are also key factors affecting rational investment in microgrid. Microgrid boasts great application value in improving the power supply reliability for important users or solving the problems of power supply in central urban and rural areas where it is difficult to expand electric capacity of and upgrade the distribution grids.

\section{Composition of Microgrid's Comprehensive Benefits}

(1) Economic benefits. Electricity selling is the most direct source of its benefits, and the ultimate yield rate is determined by the income of electricity selling, the cost of daily maintenance and also the cost of buying electricity from outside.

(2) Benefits in energy saving and emission reduction. Microgrid includes many distributed energy such as wind, solar, and storage, whose construction helps to reduce the emissions of $\mathrm{SO} 2, \mathrm{CO} 2$, nitric oxides, smoke and dusts. Its benefits in energy saving and emission reduction can be obtained by calculating the reduced emissions of pollutants or the trade value of carbon emissions.

(3) Benefits in improving reliability. It can improve the quality and reliability of electricity and the voltage quality of distribution grids and mitigate the effect of power failure and external attack on grid

${ }^{*}$ Manuscript received June 20, 2015; revised August 4, 2015.

Corresponding author. Tel.: 86-15810081297; E-mail address: jinxiaoling@sgeri.sgcc.com.cn.

doi: $10.12720 /$ sgce. $4.3 .255-260$ 
security.

(4) Deferral of investment in upgrading and renovating distribution grids. It can mitigate the obstruction of transmission and distribution grids and lower their capacity demand.

(5) Reduce the loss of distribution grids. Through technogical renovation of conventional grids, microgrid strengthens the framework of grids and ensures the qualified rate of grid loss and voltage quality. Therefore, the electric benefit brought by reducing grid losses is also its indirect benefits and it can be represented by the difference value between the grid losses before and after construction in terms of value.

(6) We can replace inefficient power plants with renewable energy or thermal-electric power plants, thus improving the efficiency of energy transformation and environmental protection.

(7) Benefits in saving resources. Natural resources such as coal and diesel are replaced by renewable energy in microgrid system. Its comprehensive energy utilization can avoid the cost caused by continuous resources consumption in the future. From the perspective of the opportunity cost, we can also consider its benefits in saving resources as the indirect benefits that microgrid brings.

On the other hand, microgrid will increase the costs of the power system to some extent, including: (1) extra losses of distribution grids (increasing the costs of electricity distribution companies); (2) receive the distributed electricity required by distributed generation/upgrading grids (restricted by heat value, voltage and short circuit, etc.); (3) extra costs of electricity balance and support services (especially intermittent and uncontrollable electricity such as wind power and solar power); (4) increased voltage (increasing the costs of electricity distribution companies).

\section{National Economic Evaluation of Microgrid}

\subsection{Method of national economy evaluation}

From the foregoing, microgrid displays more benefits in saving energy, reducing losses and environmental protection, i.e. comprehensive benefits for the whole society. Hence, the economic evaluation on microgrid should not be limited to its finance only. We should also analyze its net contributions to the national economy and evaluate its rationality to the national economy according to the principle of reasonable resources distribution from the perspective of the whole society.

With the method used to evaluate its national economy, this paper is devoted to calculating the benefits and expenses of evaluated items by specific national parameters and various benefits it brings to the country and the society according to the principle of reasonable resources distribution. In the process, we regard the whole country and the society as beneficiaries. Shadow price and shadow exchange rate determined by the opportunity cost are adopted by in the evaluation. The standard yield rate used is social yield rate. In this process, we need not calculate the expenses in financial evaluation such as taxes and loan interest and the revenues like subsidies granted for policy consideration. We should take into consideration comprehensively its contributions to national economy, social development and improving people's livelihood when calculating its benefits. Its parameters are such economic parameters as net present value, internal rate of return and dynamic investment pay-back period.

We should observe the following principles when evaluating and calculating its benefits (1) we should observe the principle of the opportunity cost any analyze the opportunity cost of occupying all resources when calculating the economic expenses invested; (2) we should observe the principle of willingness to pay and analyze the value that the members in a society is willing to pay for the output benefits when calculating the positive effect of its output; (3) we should observe the principle of willingness to accept compensation and analyze the amount of compensation that the members in a society is willing to accept when calculating the negative effect of its output; (4) If the good or service is in a competitive market, its market price is an indicator of the willingness to pay and the opportunity cost. Therefore, we should calculate the economic value of the input and output according to its market price. 


\subsection{Analysis of costs}

We should evaluate its national economy and analyze the factors affecting the benefits of microgrid by considering the effect of power supply, microgrid, connection to power grid and standby power grid on the construction and operational cost of microgrid, including:

(1) construction and operational costs of generator

We should analyze the power supply that meets the definition and characteristics of microgrid and calculate its generation costs, mainly including construction and operational costs of various power supplies and their generating capacity, etc.

(2) construction and operational costs of microgrid

We should calculate the construction and operational costs of microgrid according to the actual composition of microgrid, mainly including energy storage and control devices, the construction and operational costs of relevant grids within microgrid. Meanwhile, we should take into account the operational loss of grids and the loss of electricity in energy storage devices.

(3) costs of relevant power grid expansion and reserve

Since that microgrid can almost meet the need of electricity demand by itself, and that power grid can only provide part of its reserve capacity for grid-connected microgrid, we should calculate the costs of standby projects to connect microgrid, including the construction cost of standby grids (comprehensive costs of electricity transmission and transformation) and the cost of central generation.

(4) focus of the cost-benefits comparison of different type of microgrid

In terms of off-grid microgrid, we should compare the construction and operational costs of microgrid and load connected to power grid; in terms of grid-connected microgrid, we should compare its costs with the construction and operational costs of direct connection of microgrid to distributed generation.

\subsection{Analysis of benefits}

As mentioned in Chapter 2, the benefits of this project include both direct and indirect benefits. Direct benefits refer to the economic benefits of electricity production, while indirect benefits include the benefits of saving primary energy, reducing carbon emissions, saving transmission cost by localized distributed generation and boosting the development of relevant industries, etc.

\section{Case study}

We will comment on its national economy through 2 typical grid-connected and off-grid microgrid cases.

Table 1. Main economic parameters of project A

\begin{tabular}{|l|l|l|}
\hline & \multicolumn{1}{|c|}{$\begin{array}{c}\text { load is connected to } \\
\text { power grid }\end{array}$} & \multicolumn{1}{|c|}{$\begin{array}{c}\text { load is connected to } \\
\text { microgrid }\end{array}$} \\
\hline Total construction cost(unit: million RMB) & 8.1 & 6.595 \\
\hline Operational cost(unit: million RMB/year) & 0.225 & 0.193 \\
\hline Other costs & $\begin{array}{l}\text { Generation cost } \\
0.105 \text { million RMB/year }\end{array}$ & $\begin{array}{l}\text { Storage device } \\
1 \text { million RMB/5 years }\end{array}$ \\
\hline Generation hours (h) & - & $\begin{array}{l}\text { PV:1360 } \\
\text { Wind Power: } 2030\end{array}$ \\
\hline $\begin{array}{l}\text { Actual annual generating(utilization) capacity(unit: } \\
\text { MWh) }\end{array}$ & 239 & 239 \\
\hline $\begin{array}{l}\text { Expenses of grid connection } \\
\text { unit: million RMB) }\end{array}$ & $7.1($ over 40km, 35kV) & 0 \\
\hline $\begin{array}{l}\text { Construction cost of power generator/grids } \\
\text { unit: million RMB) }\end{array}$ & 0.6 & 0 \\
\hline Indirect benefits & 0 & 0 \\
\hline Light abandon(unit: MWh) & 0 & 0 \\
\hline Cost price of electricity (RMB/ $\mathrm{kWh)}$ & 4.05 & 3.76 \\
\hline
\end{tabular}




\subsection{Project A: off-grid microgrid}

This off-grid microgrid is planning to establish a $150 \mathrm{kWp}$ PV generation system and a $20 \mathrm{~kW}$ wind power plant, with storage configuration of $100 \mathrm{~kW} \times 2 \mathrm{~h}$ lithium-ion batteries

Scheme A: load is directly connected to power grid. Scheme B: load is connected to microgrid. The following table shows the comparison results of these two schemes.

Through estimation, if the national economy of project $\mathrm{A}$ is to meet the requirement of $8 \%$ social discount rate, unit electricity cost of project $\mathrm{A}$ is $¥ 3.76 / \mathrm{kWh}$, superior to the scheme of local load directly connected to power grid.

Grid connection expense is a direct factor affecting the economy of off-grid microgrid. When the grid connection expense of this project is $¥ 7.1$ million, it is more economic to establish off-grid microgrid. Through comprehensive estimation, off-grid microgrid begins to show its economic benefits in longdistance power supply (exceeding the permitted supply distance by $10 \mathrm{kV}$ ).

\subsection{Project B: grid-connected microgrid}

Project B is planning to construct 15 transformers of $10 \mathrm{kV} / 0.4 \mathrm{kV}$ in 9 regions, with a capacity of 1,250 $\mathrm{kVA}$ of each; the maximum generating capacity of the photovoltaic project is $13.4 \mathrm{MWp}$; it is equipped with $6 \mathrm{MW} / 4 \mathrm{~h}$ lithium batteries as storage devices; the grid is connected to local $10 \mathrm{kV}$ distribution stations to through 3 -way $10 \mathrm{kV}$ cables.

Scheme A: PV generator is directly connected to power grid. Scheme B: construct microgrid. The following table shows the comparison results of these two schemes.

Table 2. Main economic parameters of project B

\begin{tabular}{|l|l|l|}
\hline & \multicolumn{1}{|c|}{ PV connect to Power grid } & \multicolumn{1}{|c|}{ microgrid } \\
\hline Total construction cost(unit: million RMB) & 338.4 & 432.4 \\
\hline Operational cost(unit: million RMB/year) & 1.09 & 6.92 \\
\hline Other costs & 0 & $\begin{array}{l}\text { Storage device } \\
108 \text { million RMB/5 years }\end{array}$ \\
\hline Generation hours (h) & 1179 & 960 \\
\hline Actual annual generating capacity(unit: MWh) & $15800 / 12640$ & 12960 \\
\hline $\begin{array}{l}\text { Expenses of grid connection } \\
\text { unit: million RMB) }\end{array}$ & 0.45 & 1.35 \\
\hline $\begin{array}{l}\text { Construction cost of power grid upgrading } \\
\text { unit: million RMB) }\end{array}$ & 86.8 & 18.9 \\
\hline $\begin{array}{l}\text { Indirect benefits } \\
\text { Light abandon(unit: MWh) }\end{array}$ & $\begin{array}{l}\text { Energy conservation: } 0.3 \mathrm{RMB} / \mathrm{kWh} \\
\text { Carbon tax: } 10 \text { RMB /ton }\end{array}$ & $\begin{array}{l}\text { Energy conservation: } 0.3 \mathrm{RMB} / \mathrm{kWh} \\
\text { Carbon tax } 10 \mathrm{RMB} / \text { ton }\end{array}$ \\
\hline Cost price of electricity (RMB/ kWh) & 0 & 2840 \\
\hline
\end{tabular}

Through estimation, if the national economy of project $\mathrm{B}$ is to meet the requirement of $8 \%$ social discount rate, unit electricity cost of project $\mathrm{B}$ is $¥ 3.76 / \mathrm{kWh}$, lower to the scheme of PV directly connected to power grid. The main reason is:

(1) Higher initial costs of microgrid construction

The national economic cost of microgrid construction is higher than that of photovoltaic generation direct connection. Through analysis, we find the reason is that microgrid requires higher investment in storage devices, lower cost of grid connection and standby facilities and $27.7 \%$ higher comprehensive investment, compared with photovoltaic generation direct connection.

(2) Lower generating capacity of microgrid

There are light abandon since microgrid can by and large balance the exchange of system electricity (less than 20\%). The light abandon reaches as high as $17.8 \%$, thus wasting resources.

(3) Higher operational costs of microgrid than direct investment

The operational cost of microgrid is higher than that of power grid (marginal cost); meanwhile, 
microgrid also requires higher operational cost of storage devices and microgrid management, a short lifetime of storage devices and regularly changed devices during its operation, thus a higher cost.

(4) Higher cost of microgrid than photovoltaic connection in comprehensive estimation

Through estimation, if its national economy is to meet the requirement of social discount rate, its price cost is about $¥ 4.79 / \mathrm{kWh}, 223 \%$ of $¥ 2.11 / \mathrm{kWh}$ from direct photovoltaic connection.

\subsection{Analysis of affecting factors}

Through the analysis of various costs, expenses and revenues that compose the national economy of microgrid, we can conclude as follows:

(1) Microgrid costs. Distributed generation is an emerging technology, whose device and installation costs remain its main costs. And the costs of fuel cells, household small blowers and photovoltaic generation are obviously higher than other costs, thus affecting the whole economy of microgrid. Wind energy and solar power have randomness and volatility. The inland cities in central China witness a lower effective wind speed throughout the year which restricts the utilization hours of wind power devices within microgrid; meanwhile, distributed renewable energy needs to achieve its smooth power fluctuations in real time through storage and control and protective devices and maintain its power balance and system stability, thus increasing the equipment costs of microgrid. Wind and solar power supply well equipped within microgrid will restrict its overall economy.

(2) Revenues of microgrid. The reliability of microgrid accounts for a large proportion of its revenues. Microgrid plays an important role in improving the reliability or receiving-end grids and power supply for users. With the expansion of grids, microgrid can improve the reliability of power supply for important users in case high-voltage transmission grids are broken by natural disasters or they break down and reduce the losses brought by power failure considerably. As a platform for distributed renewable energy to be connected to grids, microgrid plays an essential role in energy saving and emission reduction. The losses of environmental pollution and treatment expenses vary greatly in different cities and in different development stages. Nevertheless, clean and low-emission power supply becomes more competitive along with top priority and policy support to energy saving and emission reduction from our country.

(3) The importance of users' load and the construction site of microgrid are key factors affecting rational investment in microgrid. Equipped with the same power supply, the more important of users' load, the higher unit capacity costs of grid expansion are, and the more obvious of microgrid's economy. Hence, microgrid has a great application value in improving the power supply reliability of important users (e.g. banks, hospitals, iron and steel companies) or solving the problems of power supply in the places where grid expansion requires high costs (central urban areas, rural areas and isolated islands where it is densely loaded and it is difficult to expand and renovate its capacity).

\section{Conclusion}

Although the construction costs of microgrid are higher, it is economic to invest in microgrid in view of its social benefits in improving reliability, energy saving and emission reduction, environmental protection and deferral of investment in transmission and distribution grids.

Equipped with the same power supply, the more important of users' load, the higher unit capacity costs of grid expansion are, and the more obvious of microgrid's economy. Microgrid has a great application value in improving the power supply reliability of important users (e.g. banks, hospitals, iron and steel companies) or solving the problems of power supply in central urban areas and rural areas where it is difficult to expand and renovate its capacity).

Off-grid microgrid is suitable to the places where the costs of power supply are high, including such areas far from power grid as pasturing and forest areas as well as isolated islands whose costs of power supply are high. At the current construction cost, grid-connected microgrid has no national economy. We should take into consideration other factors like the requirements for power supply quality and demo test.

The beneficiaries of microgrid. The benefits in grid losses and deferral of transmission and distribution 
construction belong to grid companies, while its benefits in reliability and cooling-heating are social benefits. Its social benefits are higher than its economic benefits. And its development needs to be jointly propelled by all stakeholders.

\section{References}

[1] Lu ZX, Wang CX, Min Y, et al. Overview on microgrid research. Automation of Electric Power Systems, 2007; 31(19):100107.

[2] Niu M, Huang W, Guo J, et al. Research on economic operation of grid-connected microgrid. Power System Technology, 2010; 34(11):38-42.

[3] Chen J, Wang CS, Zhao B, et al. Economic operation optimization of a stand-alone microgrid system considering characteristics of energy storage system. Automation of Electric Power Systems, 2012; 36(20):25-31.

[4] Costa PM, Matos MA. Economic analysis of micro grids including reliability aspects. In: Proc. 9th International Conference on Probabilistic Methods Applied to Power Systems, Stockholm, 2006:1-8.

[5] Tsikalakis AG, Hatziargyriou ND. Financial evaluation of renewable energy source production in microgrids markets using probabilistic analysis. In: Proc. IEEE Russia Power Tech, 2005:1-7.

[6] Pudjianto D, Strbac G. Investigation of regulatory, commercial, economic and environmental issues in microgrids. In: Proc. International Conference on Future Power Systems, Amsterdam, 2005.

[7] Moises CP, Matos MA. Economic analysis of microgrids including reliability aspects. In: Proc. International Conference on Probabilistic Methods Applied to Power Systems, Stockholm, 2006.

[8] Papathanassiou S, Hatziargyriou N, Kai S. A benchmark low voltage micogrid network. Power Systems with Dispersed Generation, 2005; 20(3):1447-1455. 